\title{
ReviewArticle
}

\section{Radiation Induced Second Malignancies (RISM): Risk, Diagnosis, Treatments and Review of Literature}

\begin{abstract}
MN Haque ${ }^{1}$, ASMJ Chowdhury ${ }^{2}$, MY Ali ${ }^{3}$
Abstract:

Information concerning radiation-induced malignancies comes from the A-bomb survivors and from medically exposed individuals, including second malignancies in radiation therapy patients. The A-bomb survivors show an excess incidence of carcinomas in tissues such as the gastrointestinal tract, breast, thyroid, and bladder, which is linear with dose up to about $2.5 \mathrm{~Sv}$. There is great uncertainty concerning the dose-response relationship for radiationinduced carcinogenesis at higher doses. Some animal and human data suggest a decrease at higher doses, usually attributed to cell killing; other data suggest a plateau in dose. Modern treatment modalities such as passive proton therapy and intensity modulated radiation therapy (IMRT) produce large amounts of scatter, leakage and neutron radiation, which has been found to be directly proportional to the risk of second malignancy incidence. Organs closer to the target typically receive higher and less homogeneous doses of cell killing and repopulation effects play an increasing role. The most common type of cancer caused by radiation is sarcoma, which is typically a cancer of muscle, bone, or blood vessel origin. We reviewed the literature with key words "Radiation induced second malignancies, second primary tumour, second cancer" to find relevant articles describing risk, diagnosis and treatments of radiation induced second malignancies.
\end{abstract}

Key words: Radiation, Second malignancy, Second primary cancer, Second cancer;

\section{Introduction:}

It may be difficult to distinguish between radiationinduced cancers, late recurrences after radiation and second primary tumors that develop despite radiation. The definition of a radiation-induced cancer was established by Cahan in 1948 and specifies that a radiation induced cancer must occur within the treatment field, have a significant latency and be a different kind of cancer than the original type ${ }^{1}$.

The high frequency of second primary cancers appearing in patients with squamous cell carcinoma of the head and neck confounds analysis in this region largely due to field cancerization, often of a similar type. Although higher rates have been reported in the past, a study from 1999 identified second malignancies to develop at a rate of $2.3 \%$ per year in the respiratory and upper tracts of 1609 patients with early stage squamous cell carcinoma of the head and neck ${ }^{2}$.

1. Dr. Md. Nizamul Haque MBBS, FCPS (Radiotherapy), M.Phil (Oncology), Associate Professor \& Head, Department of Radiotherapy, Faridpur Medical College, Faridpur.

2. Professor ASM Jahangir Chowdhury, MBBS, MS (Ortho), Professor \& Principal, Faridpur Medical College, Faridpur.

3. Professor Md. Yusuf Ali MBBS, FCPS (Medicine), Professor \& Head, Department of Medicine, Faridpur Medical College, Faridpur.

Address of correspondence :

Dr. Md. Nizamul Haque MBBS, FCPS (Radiotherapy), M.Phil (Oncology), Associate Professor \& Head, Department of Radiotherapy, Faridpur Medical College, Faridpur.

Phone: +8801730302100, E-mail: haquenizamuldr@gmail.com
The risk of developing a second cancer for head and neck cancer patients treated surgically was $2.2 / 1000$ person per year compared to $2.9 / 1000$ person per year among those treated with radiation. The risk of a second cancer has been shown to increase with time and radiation dose with the latency before appearance of a second cancer differing between organs. The risk of cancer of the rectum and bladder starts to increase 10 years after exposure, whereas leukaemia develops within 2-3 years after exposure with a peak at 5 to 6 years ${ }^{3}$.

\section{Radiation induced Risk of Second Malignancies:}

\section{Risk of breast cancer after chest irradiation}

Whole-lung irradiation confers greater risk of breast cancer than previously recognized ${ }^{4}$. In women with a history of radiotherapy (RT) for Hodgkin's Lymphoma (HL), breast cancer is diagnosed at an earlier stage, but these women are at greater risk for bilateral disease and are also at increased risk of metachronous contralateral breast cancer ${ }^{5}$. For developing breast cancer as $2^{\text {nd }}$ malignancy, 136-fold increase for girls who received RT before the age of 15 years and no increased risk for women treated after age $30^{6}$. 


\section{Risk of $2^{\text {nd }}$ cancer after breast irradiation}

Breast cancer patients experience a small but significant risk of developing second non-breast cancer after radiotherapy treatmen ${ }^{7}$ YYoung patients $(<50)$ higher lung cancer; older patients $(>50)$ higher soft tissue sarcoma (STS)\}. RT associated with increased risk of sarcoma, but magnitude of risk is small. Angiosarcoma has significantly more prevalent ${ }^{8}(15-$ year sarcoma incidence RT $0.3 \%$ vs. no RT $0.2 \%$ ). Following radiation treatment of breast cancer, RT is associated with higher risk of developing sarcoma ${ }^{9}$.

\section{Risk of $2^{\text {nd }}$ primary cancer after pelvic irradiation}

Risk of second cancers after radiotherapy for cervical cancer is small but significant; benefit of RT outweighs the $\operatorname{risk}^{10}\left\{2^{\text {nd }}\right.$ cancers $(1 \%), 1.6 \%$ excess risk per person per decade, cumulative risk $24 \%$ at 30 years $\}$. In case of testicular cancer, RT and chemotherapy increase risk of second malignancies (SMN) \{second malignancies $(10 \%)$, risk $1.7 \mathrm{x}$ over general population and SMN by modality: sub-diaphargmatic RT $2.6 \mathrm{x}$, chemo $2.1 \mathrm{x}$ over surgery alone $\}^{11}$. For patients diagnosed at age 35 years, cumulative risks of solid cancer to age 75 years were $36 \%$ (seminoma) and $31 \%$ (nonseminomas), compared with $23 \%$ for the general population ${ }^{12}$.

Risk of $2^{\text {nd }}$ malignancies after radiation (other site) therapy

Risk of second cancer (SC) associated with younger age at HD diagnosis, largest risk for breast, other supradiaphragmatic sites, infradiaphragmatic, malignant mesothelioma ${ }^{13}\{30 \mathrm{yr}$ risk for solid cancer $18 \%$ (men) $/ 26 \%$ (women) for patients diagnosed at age 30 , vs $7 \% / 9 \%$ general population $\}$. In Ewing's sarcoma, overall risk of $2^{\text {nd }}$ malignancies similar to other pediatric tumors ${ }^{14}$ (20-year cumulative incidence: $9.2 \%$ for any malignancy, $6.5 \%$ for sarcoma, doseresponse: none in $<48 \mathrm{~Gy}, 130 / 10,000$ for $>60 \mathrm{~Gy}$ ). Neurofibromatosis 1(NF1) patients with optic glioma (OPG) treated with RT alone or in combination (Dose 25-50 Gy), significantly increased $2^{\text {nd }} \mathrm{CNS}$ cancer risk in NF1 patients with $\mathrm{OPG}^{15}$. Childhood cancer survivors has substantial and increasing risk for second neoplasms ${ }^{16}$ (Second malignancy rate 6\%, 30-year cumulative incidence of SMN 9\%, nonmelanoma skin cancer $7 \%$, risk elevated after $>20$ years and risks differs by subtype).

\section{Diagnosis:}

\section{Imaging}

Magnetic Resonance Imaging (MRI) and Computed Tomography (CT) are the imaging modalities of choice to evaluate and follow or to look for distant spread of the disease. Imaging features are not pathognomonic and can be difficult to interpret. It can be very difficult to exclude a recurrence of the primary tumor when relying on imaging alone ${ }^{17}$.

\section{Pathological findings}

Core needle biopsy is mandatory in confirming the diagnosis. The biopsy will distinguish between a new malignancy, recurrence of the primary malignancy, and post-operative or post-radiotherapy changes. Biopsy will also indicate the histologic subtype and grade of the disease.

\section{Molecular biology}

Very little is known about the genetic changes involved in the tumorigenesis of postirradiation sarcomas. According to a recent study and review by Mertens et al regarding cytogenetic changes in Radiation Induced Sarcoma (RIS), these tumors have complex karyotypes, with loss of 3p21-pter being more frequent than in sporadic sarcomas. Also, polyclonal tumors with neardiploid chromosome numbers (few or no karyotypic abnormalities) were observed ${ }^{18}$.

\section{Treatments:}

\section{Surgery}

Radical resection with negative histological margins (R0) is the treatment of choice for localized disease. Surgical resection includes wide excision, limb-sparing surgery or forequarter amputation etc. Previous irradiation impairs anatomic and tumor planes, preventing surgeons from appreciating true tumor margins. This further reinforces the necessity for aggressive and wide resection, especially considering that a positive surgical margin will reduce survival by nearly half ${ }^{19}$.

Major plastic surgical reconstruction can be required, ranging from split thickness skin grafting to local flaps and free tissue transfer. Sometimes it is necessary to reconstruct the chest or abdominal wall using a polypropylene mesh and methyl methacrylate sandwich technique $^{20,21}$. Due to the high incidence of multifocal RIS after breast cancer treatment, in particular breast angiosarcoma post-radiation and breast-conserving therapy (BAPBCT), a surgeon might consider removing the entire irradiated area and not just the tumor $^{22}$.

\section{Radiation therapy}

Additional radiation therapy using modern techniques may be considered ${ }^{23}$, but there are concerns about toxicity, as repeated high-dose radiotherapy is often impossible due to limited bone marrow function. Data from case reports have been published on hyperfractioned radiotherapy for BAPBCT ${ }^{11}$ showing 
certain efficacy. BAPBCT tumors have a high growth rate, making them more likely to repopulate between daily fractions of radiotherapy. The use of multiple daily fractions might, therefore, prevent repopulation from occurring ${ }^{24}$.

\section{Chemotherapy}

For metastatic disease, palliative chemotherapy is the treatment of choice for the majority of the diseases and anti-angiogenic drugs, such as sorafenib and sunitinib, have shown some efficiency in angiosarcomas ${ }^{25}$.

Chemotherapy can be administered in the neoadjuvant setting, before surgical resection, to improve local control and eradicate subclinical metastatic disease.

\section{Conclusion:}

Since the majority of cancer patients receive radiotherapy, it is critical that clinicians are aware of the potential development of radiation induced $2^{\text {nd }}$ malignancy, which can occur decades after radiotherapy. Any abnormality should be biopsied, and if a cancer is detected, the treatment of choice is surgical resection with negative margins. Future studies analyzing clinical and pathological characteristics of primary tumors, and breast cancers in particular, can help to identify factors that predispose to Radiation Induced Second Malignancies (RISM) for better selection of patients undergoing radiotherapy. Another issue is to examine is the genetics of RISM, which may illuminate the mechanisms responsible for carcinogenesis.

\section{References :}

1. Cahan WG, Woodard HQ, Higinbotham NL, Stewart FW, Coley BL. Sarcoma arising in irradiated bone: report of eleven cases. Cancer 1948; 1:3-29

2. Leon X, Quer M, Diez S, et al. Second neoplasmin patients with head and neck cancer. Head Neck 1999; 21:204-10

3. Amemiya K, Shibuay H, Yoshimura R, Okada N. The risk of radiation-induced cancer in patients with squamous cell carcinoma of the head and neck and its results of treatment. The British Journal of Rdiology 2005; 78: 1028-33.

4. Moskowitz CS, Chou JF, Wolden SL, Bernstein JL, Malhotra J, Novetsky FD, et al. Breast cancer after chest radiation therapy for childhood cancer. J Clin Oncol. 2014; 32(21):2217-23.

5. Elkin EB, Klem ML, Gonzales AM, Ishill NM, Hodgson D, Ng AK, et al. Characteristics and Outcomes of Breast Cancer in Women With and Without a History of Radiation for Hodgkin's Lymphoma: A Multi-Institutional, Matched Cohort Study. J Clin Oncol. 2011; 29(18):2466-73.

6. Hancock SL, Tucker MA, Hoppe RT. Breast cancer after treatment of Hodgkin's disease. J Natl Cancer Inst. 1993; 85(1):25-31.

7. Schaapveld M, Visser O, Louwman MJ, deVries EG, Willemse PH, Otter R et al. Risk of new primary nonbreast cancers after breast cancer treatment: a Dutch population-based study. J Clin Oncol. 2008; 26(8):1239-46.
8. Yap J, Chuba PJ, Thomas R, Aref A, Lucas D, Severson RK, et al. Sarcoma as a second malignancy after treatment for breast cancer. Int J Radiat Oncol Biol Phys. 2002; 52(5):1231-7.

9. Taghian A, de Vathaire F, Terrier P, Le M, Auquier A, Mouriesse H, et al. Long-term risk of sarcoma following radiation treatment for breast cancer. Int J Radiat Oncol Biol Phys. 1991; 21(2):361-7.

10. Ohno T, Kakinuma S, Kato S, Tsujii H, Shimada Y. Long-term survival and risk of second cancers after radiotherapy for cervical cancer. Int J Radiat Oncol Biol Phys. 2007; 69(3):740-5.

11. van den Belt-Dusebout AW, Nuver J, de Wit R, Gietema JA, ten Bokkel HWW, Rodrigus PT, et al. Treatment-specific risks of second malignancies and cardiovascular disease in 5-year survivors of testicular cancer. J Clin Oncol. 2007; 25(28):4370-8.

12. Travis LB, Fosså SD, Schonfeld SJ, McMaster ML, Lynch CF, Storm H, et al. Second cancers among 40,576 testicular cancer patients: focus on long-term survivors. J Natl Cancer Inst. 2005; 97(18):1354-65.

13. Hodgson DC, Gilbert ES, Dores GM, Schonfeld SJ, Lynch CF, Storm H, et al. Long-Term Solid Cancer Risk Among 5-Year Survivors of Hodgkin's Lymphoma. J Clin Oncol. 2007; 25(12): 1489-97.

14. Kuttesch JF, Wexler LH, Marcus RB, Fairclough D, WeaverMcClure L, White M, et al. Second malignancies after Ewing's sarcoma: radiation dose-dependency of secondary sarcomas. J Clin Oncol. 1996; 14(10):2818-25.

15. Sharif S, Ferner R, Birch JM, Gillespie JE, Gattamaneni HR, Baser ME, et al. Second primary tumors in neurofibromatosis 1 patients treated for optic glioma: substantial risks after radiotherapy. J Clin Oncol. 2006; 24(16):2570-5.

16. Meadows AT, Friedman DL, Neglia JP, Mertens AC, Donaldson SS, Stovall M, et al. Second neoplasms in survivors of childhood cancer: findings from the Childhood Cancer Survivor Study cohort. J Clin Oncol. 2009; 27(14):2356-62.

17. SheppardDG and Libshitz HI. Post-radiation sarcomas: a review of the clinical and imaging features in 63 cases. Clin Radiol. 2001; 56: $22-29$.

18. Mertens F, Larramendy M, Gustavsson A, Gisselsson D, Rydholm A, BrosjoO, et al. Radiation-associated sarcomas are characterized by complex karyotypes with frequent rearrangements of chromosome arm 3p. Cancer Genet Cytogenet. 2000; 116: 89-96.

19. Gladdy R A, Qin L X, Moraco N, Edgar MA, Antonescu CR, Alektiar KM, et al. Do radiation-associated soft tissue sarcomas have the same prognosis as sporadic soft tissue sarcomas? J Clin Oncol. 2010; 28: 2064-69.

20. Bellon JM, Bujan J, Contreras LA, Carrera-San Martin A, and Jurado F. Comparison of a new type of polytetrafluoroethylene patch (Mycro Mesh) and polypropylene prosthesis (Marlex) for repair of abdominal wall defects. J Am Coll Surg.1996; 183: 11-18.

21. NetscherDT and BaumholtzMA. Chest reconstruction:Anterior and anterolateral chest wall and wounds affecting respiratory function. Plast Reconstr Surg. 2009; 124: 240-52.

22. Holt GE, Thomson AB, Griffin AM, Bell R, Wunder J, Rougraff $\mathrm{B}$, et al. Multifocality and multifocal post-radiation sarcomas. Clin Orthop Relat Res. 2006; 450: 67-75.

23. Kasperts N, Slotman BJ, Leemans CR, de BreeR, Doornaert P,Langendijk JA. Results of postoperative re-irradiation for recurrent or second primary head and neck carcinoma. Cancer2006; 106: 1536-47.

24. AbbottR and Palmieri C. Angiosarcoma of the breast following surgery and radiotherapy for breast cancer. Nat Clin Pract Oncol, 2008; 5: 727-36.

25. Penel N, Marreaud S, Robin YM, Hohenberger P. Angiosarcoma: State of the art and perspectives. Crit Rev Oncol Hematol. 2011;80:257-63. 